ery vividness, and absorption: A multidimensional study. Journal of Personality \& Social Psychology, 42, 915-926.

FeLDT, L. S. (1961). The use of extreme groups to test for the presence of a relationship. Psychometrika, 26, 307-316.

Kinlstrom, J. F., Guisky, M. L., Peterson, M. Q., Harvey, E. M., \& Rose, P. M. (1991). Vividness and control of imagery: A psychometric analysis. Journal of Mental Imagery, 15, 133-142.

MARKs, D. F. (1973). Visual imagery differences in the recall of pictures. British Journal of Psychology, 64, 17-24.

Marks, D. F. (1983). Mental imagery and consciousness: A theoretical review. In A. A. Sheikh (Ed.), Imagery: Current theory, research, and application (pp. 96-130). New York: Wiley.

MARKs, D. F. (1989). Construct validity of the Vividness of Visual Imagery Questionnaire. Perceptual \& Motor Skills, 69, 459-465.

McKelVIE, S. J. (1979). Effects of instructions and format on reported visual imagery. Perceptual \& Motor Skills, 49, 567-571.

MCKelviE, S. J. (1984). Reported visual imagery for faces and facial recognition memory. Perceptual \& Motor Skills, 59, 825-826.

MCKelvie, S. J. (1986). Effects of format of the Vividness of Visual Imagery Questionnaire on content validity, split-half reliability, and the role of memory in test-retest reliability. British Journal of Psychology, 77, 229-236.

McKelvie, S. J. (1990). The Vividness of Visual Imagery Questionnaire: Commentary on the Marks-Chara debate. Perceptual \& Motor Skills, 70, 551-560.
Narchal, R., \& Broota, K. D. (1988). Sex differences in vividness of visual imagery under eyes open and closed conditions. Journal of Mental Imagery, 12, 81-88.

RichARDSON, A. (1979) Dream recall frequency and vividness of visual imagery. Journal of Mental Imagery, 3, 65-72.

Sheehan, P. W. (1967). A shortened form of the Betts' Questionnaire Upon Mental Imagery. Journal of Clinical Psychology, 23, 386-389.

SOMmer, R. (1980). Strategies for imagery research. Journal of Mental Imagery, 4, 115-121.

WallaCE, B. (1984). Creation of the horizontal-vertical illusion through imagery. Bulletin of the Psychonomic Society, 22, 9-11.

Wallace, B., Persanyi, M. W., Gerboc, B. (1989). Imagery, hypnosis and the creation of subjective contours. Journal of Mental Imagery, 13, 139-152.

White, K. D., Ashton, R., LAW, H. (1978). The measurement of imagery vividness: Effects of format and order on the Betts' Questionnaire Upon Mental Imagery. Canadian Journal of Behavioural Science, 10, 68-78.

White, K. [D.], Sheehan, P. W., \& Ashton, R. (1977). Imagery assessment: A survey of self-report measures. Journal of Mental Imagery, 1, 145-170.

(Manuscript received February 24, 1992.)

\title{
Seventh International Conference on Event Perception and Action Vancouver, B.C., Canada August 8-13,1993
}

The International Society for Ecological Psychology and the Psychology Department of the University of British Columbia are sponsoring the Seventh International Conference on Event Perception and Action to be held at the Conference Centre on the University of British Columbia campus.

This conference will present paper and poster sessions on a wide variety of topics, including, but not limited to, ecological acoustics, perceptual and cognitive development, perceptual guidance of locomotion, analysis of intentional systems, and ecological approaches to social psychology.

To have your name placed on the mailing list for the call for papers or for further information, contact John B. Pittenger, Department of Psychology, University of Arkansas at Little Rock, 2801 South University Avenue, Little Rock, AR 72204 (telephone 501-569-3171, e-mail icepa7@ualr.edu). 